- Occlusal deterioration occurs in the period that follows orthodontic retention.

- Dual arch fixed appliance treatment achieves the best post-treatment results.

- Dual arch fixed appliance treatment maintains the best post-retention results.

- Eighty-four per cent of patients in this cohort still had demonstrable benefit from orthodontic treatment after a mean of 6.5 years post-retention.

\title{
The long-term benefits of orthodontic treatment
}

\author{
R. A. Linklater ${ }^{1}$ and N. A. Fox ${ }^{2}$
}

Objective This study aimed to evaluate post-treatment changes at least five years out of retention in a cohort of 100 consecutively started patients treated by a postgraduate student in a UK orthodontic department.

Design Analysis of study models using recognised occlusal indices. Setting Patients initially treated at Newcastle Dental Hospital were recalled for record collection.

Materials and methods Study models and clinical photographs were taken for each patient attending for post-retention records. Weighted Peer Assessment Rating (PAR) Index and Index of Orthodontic Treatment Need (IOTN) scores were recorded for cases at the beginning, end and at least 5 years post-retention.

Main outcome measures Post-treatment changes were evaluated using PAR Index and IOTN to evaluate extent and likelihood of change and to compare treatment modalities.

Results Seventy-eight patients attended for post-retention records. Overall PAR reduction immediately post-treatment was $68.6 \%$ and at a mean of 6.5 years post-retention was 55.5\%. Dual arch fixed appliance treatments achieved the greatest reduction in PAR score, and maintained the reduction beyond the retention period better than other treatment modalities. Eighty-four per cent of the cohort still had some demonstrable improvement after a mean of 6.5 years post-retention. There was a residual need for treatment in $8 \%$ of cases on aesthetic grounds and in 24\% of cases on dental health grounds.

Conclusions 0 cclusal deterioration after orthodontic treatment is almost universal. Dual arch fixed appliance treatment provides the best post-treatment and post-retention result.

The annual cost of orthodontic treatment in the General Dental Services in England and Wales is in excess of $£ 85$ million, ${ }^{1}$ and in the Community and Hospital Dental Service it is in excess of $£ 20$ million. Such a substantial investment of funds must be justified. It has been argued previously that orthodontic treatment provides

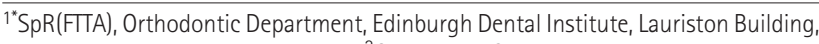
Lauriston Place, Edinburgh EH3 9YW; ${ }^{2}$ Consultant, Orthodontic Department, Middlesbrough General Hospital, Ayresome Green Lane, Middlesbrough TS5 5AZ ${ }^{*}$ Correspondence to: Rognvald Linklater

E-mail:linctus@waitrose.com
}

\section{Refereed paper}

Received 25.06.01; Accepted 15.01.02

๑ British Dental Journal 2002; 192: 583-587 only aesthetic benefit to patients ${ }^{2}$ and that matters of dental health are not addressed. The introduction of indices in orthodontics has enabled the speciality to answer that criticism successfully ${ }^{3}$ by demonstrating pre- and post-treatment changes. Since then a number of papers have been published looking at treatment need and treatment outcome. ${ }^{4,5}$ Most studies demonstrate the greatest benefit to patients at the end of treatment if fixed appliances were used in both arches. ${ }^{4}$

In the current climate of high quality, accountable, professional healthcare the demand for orthodontists to provide treatments that are evidence-based is heightening. ${ }^{6,7}$ Critical evaluation of the available evidence is needed in orthodontics to ensure the diagnoses and treatment plans offered to patients are the most appropriate. This is both in regard to the presenting occlusion and to the likely long-term stability. The exact detail regarding long-term occlusal change is incomplete. It is known that untreated individuals undergo longitudinal occlusal change. ${ }^{8-10}$ Similarly, patients treated with orthodontic appliances undergo post-treatment change. Most studies report beneficial occlusal change from treatment, ${ }^{11}$ followed by some deterioration in the quality of the occlusion in the post-treatment phase. ${ }^{12-20}$

Whilst most papers acknowledge the unpredictability of posttreatment change both in regard to its likelihood in an individual and to its extent, it would seem that about half of the total relapse occurs within the first two years post-treatment with good stability of most features in the period beyond 5 years. ${ }^{14}$ The feature found to be most prone to 'late' relapse was lower incisor imbrication. ${ }^{14-16,20}$

The Peer Assessment Rating (PAR) Index is an internationally recognised and accepted index for recording occlusal features from study models. ${ }^{21}$ It has been suggested that a good standard of orthodontic treatment should result in a mean PAR reduction of $70 \%$ or more. ${ }^{22}$ This certainly appears to be what would subjectively be called 'a clinically acceptable result'. The Index of Orthodontic Treatment Need (IOTN) indicates the need for orthodontic treatment on grounds of dental health (DHC) and aesthetics (AC). The scoring of IOTN (DHC) over time in untreated subjects has been shown to remain constant in the 11-19 year age range, but the scoring of IOTN (AC) in the same group showed a reduction in score over time. ${ }^{10}$

Although proven to be an objective, valid and reproducible index for scoring occlusal change for the entire mouth, ${ }^{22}$ the PAR 
Index has limitations for assessing treatment outcome. ${ }^{11,23}$ Factors such as facial profile, root resorption, decalcification of enamel, and the likely stability of the result are not addressed. Nevertheless, these indices have now become accepted within the orthodontic profession both in the UK and overseas as being an easy and relatively quick method of assessing orthodontic outcome.

A review of the recent literature revealed a number of papers that used the PAR Index to evaluate long-term ( $>5$ years) posttreatment change. In many instances the samples were limited to a single treatment modality ${ }^{13,19}$ and are thus not representative of mixed practice. In the general dental services it is acknowledged that a proportion of cases are discontinued, ${ }^{4}$ with limited benefit to the individual patient. Recording of patients that were not started consecutively may have led to bias in the selection of cases for inclusion, ${ }^{13,17-19}$ with the possibility that only successfully treated cases are included and unfinished cases omitted.

In addition, a substantial reduction in the size of the sample at post-retention recording ${ }^{13}$ reduces the power of these figures for comparison. The reported figures of 5-year post-retention PAR score reduction range from $63.8 \%$ to $69 \% .{ }^{13,14,17,18}$ These studies, however, are quite selective and so the figures need to be interpreted with caution. Only one of these studies reported the results of a single operator long-term. ${ }^{18}$ At present post-retention change with respect to PAR and IOTN has not been addressed in the UK.

This paper therefore aims to measure post-treatment change in an orthodontically treated cohort in the United Kingdom already examined by similar means at the end of treatment ${ }^{11}$ and one year out of retention. ${ }^{24}$ The study followed up the first 100 consecutively started cases treated by a post-graduate student in orthodontics in the United Kingdom at least 5 years post-retention to evaluate the post-treatment changes with respect to PAR and IOTN.

\section{MATERIAL AND METHOD}

The first 100 consecutive cases given to one of the authors (NF) as a post-graduate student in Orthodontics at Newcastle Dental Hospital from October 1988 were identified and current addresses obtained from the dental hospital Patient Administration System (PAS). Where patients had moved, addresses were obtained from patients' General Medical Practitioners and the Central NHS Register. After obtaining Local Ethical Committee approval a research and development grant was awarded from South Tees Acute Hospital NHS Trust. Patients were contacted and invited to attend for a record collection. As an incentive to attend patients were paid £25 following their attendance.

All cases that had orthodontic treatment started were contacted regardless of whether or not their treatment was completed. It was decided to do this so that the most representative sample of patients' treatment could be obtained. Study models and clinical photographs were obtained wherever possible. Some patients sent their study models by post, sometimes from overseas. In these cases it was not possible to obtain clinical photographs. PAR scores, IOTN (DHC and AC) were then recorded for cases at the beginning, end and at least 5 years post-retention. The examiner had attended a course of instruction in occlusal indices and had been calibrated.

Out of the 100 consecutively started patients, it was not possible to locate either the hospital notes or pre-treatment study models for five cases. Of the remaining 95, six had been in retention with bonded retainers within the last five years and were therefore excluded from the study. Of the remaining 89, 78 attended for record collection or sent study models by post.

\section{STATISTICAL ANALYSIS}

Differences in the PAR scores at the 3 treatment intervals were analysed using the Mann Whitney $U$ Test. Differences in IOTN (both DHC and $\mathrm{AC}$ ) were analysed using the Kruskal Wallis test.
A t-test was performed on the PAR scores of the 78 cases for whom post retention records were available compared with the original pre- and post-treatment sample of 100 and 92 respectively. This was to ensure there was no bias in the post-retention group. The scoring of 25 models selected at random was repeated and intraexaminer agreement confirmed using the Kappa statistic.

\section{RESULTS}

Table 1 shows the nature of the appliances used for the original 100 patients, and the breakdown of appliance types in the two follow-up groups. Investigation of intra-examiner agreement resulted in a Kappa value of 0.83 . This can be interpreted as almost perfect agreement beyond chance.

\begin{tabular}{lccc}
\multicolumn{4}{l}{ Table 1 Appliances used at each stage of treatment } \\
\hline \multicolumn{4}{c}{ RECORDS AVAILABLE AT EACH TREATMENT STAGE } \\
APPLIANCE TYPE & START & END & 5 YRS POST-RETENTION \\
\hline Dual arch fixed & 45 & 45 & 40 \\
Single arch fixed & 34 & 33 & 31 \\
Functional & 9 & 9 & 3 \\
Removable & 12 & 4 & 4 \\
Total & $\mathbf{1 0 0}$ & $\mathbf{9 2}$ & $\mathbf{7 8}$
\end{tabular}

The $t$-test on post-treatment PAR scores found that there was no statistical difference $(P>0.05)$ between the 78 patients who returned for post-retention records and the 92 patients for whom post-treatment records were available. This infers that the postretention group is representative of the original sample with respect to treatment standards. The mean post-retention time was 6.5 years with a range of 5.0-8.3 years.

The mean PAR scores at the end of treatment and at a mean 6.5 years post-retention are shown in Table 2 . It can be seen that dual arch fixed appliances produced the greatest reduction in PAR score at the end of treatment, and maintained the greatest reduction in PAR score post-retention. Post-retention values for removable and functional appliances are not presented, as the small sample size would make the values meaningless.

\begin{tabular}{lclrl}
\hline \multicolumn{4}{l}{ Table 2 Percentage PAR Reduction at end of treatment and post-retention } \\
\hline \multicolumn{5}{c}{ MEAN PAR SCORE REDUCTION } \\
APPLIANCE TYPE & END & \multicolumn{3}{c}{ 5 YEARS POST-RETENTION } \\
\hline Dual arch fixed & $79.0 \%$ & $(n=45)$ & $62.0 \%$ & $(n=40)$ \\
Single arch fixed & $54.9 \%$ & $(n=33)$ & $44.3 \%$ & $(n=31)$ \\
Functional & $72.3 \%$ & $(n=9)$ & N/A & $(n=3)$ \\
Removable & $46.3 \%$ & $(n=12)$ & N/A & $(n=4)$ \\
Total & $\mathbf{6 8 . 6 \%}$ & $(n=92)$ & $\mathbf{5 5 . 5 \%}$ & $(n=78)$ \\
\hline
\end{tabular}

Table 3 shows the improvement in cases using the criteria previously defined by Richmond et $a l .{ }^{4}$ Eighty-four per cent of cases that were followed up at a mean of 6.5 years post-retention still demonstrated clear benefit from orthodontic treatment.

\begin{tabular}{lccc}
\multicolumn{4}{c}{ Table 3 PAR score improvement at end of treatment and post-retention } \\
\hline & WORSE/NO DIFFERENT & IMPROVED & GREATLY IMPROVED \\
\hline End of treatment & $9 \%$ & $36 \%$ & $55 \%$ \\
\hline 6.5 years post retention & $16 \%$ & $53 \%$ & $31 \%$
\end{tabular}

Table 4 shows the results with respect to IOTN (DHC) and IOTN (AC). After a mean of 6.5 years post-retention, $8 \%$ of cases were in need of further treatment on aesthetic grounds 
and $24 \%$ on grounds of dental health. Another way to look at the results of Tables 3 and 4 is to say the orthodontic treatment was $84 \%$ successful at correcting the occlusion, $92 \%$ successful at improving the appearance and $76 \%$ successful at correcting dental health. The pattern of relapse was very arbitrary. The two cases below demonstrate the greatest and smallest change in PAR post retention.

\begin{tabular}{|c|c|c|c|}
\hline & START & END & 6.5 YEARS POST-RETENTION \\
\hline \multicolumn{4}{|c|}{ DENTAL HEALTH } \\
\hline $\begin{array}{l}\text { No need } \\
\text { (Grades 1-2) }\end{array}$ & $0 \%$ & $69 \%$ & $44 \%$ \\
\hline $\begin{array}{l}\text { Borderline } \\
\text { (Grade 3) }\end{array}$ & $6 \%$ & $17 \%$ & $32 \%$ \\
\hline $\begin{array}{l}\text { Definite need } \\
\text { (Grades 4-5) }\end{array}$ & $94 \%$ & $14 \%$ & $24 \%$ \\
\hline \multicolumn{4}{|l|}{ AESTHETICS } \\
\hline $\begin{array}{l}\text { No need } \\
\text { (Grades 1-4) }\end{array}$ & $0 \%$ & $76 \%$ & $62 \%$ \\
\hline $\begin{array}{l}\text { Borderline } \\
\text { (Grades 5-7) }\end{array}$ & $20 \%$ & $24 \%$ & $30 \%$ \\
\hline Definite need & $80 \%$ & $0 \%$ & $8 \%$ \\
\hline
\end{tabular}

\section{Case 1 (Fig. 1)}

This case represents a Class II Division 1 malocclusion with severe crowding in both arches (Pre-treatment PAR score 53, DHC 5a and AC 9). Following treatment with upper and lower pre-adjusted edgewise appliances, headgear and extraction of first premolars, his PAR score was reduced to 3 (94\% reduction), his DHC to $2 \mathrm{~g}$ and his AC score to 1 . He was retained with upper and lower Hawley retainers full-time for 6 months, then nighttime for a further 6 months with headgear support. At 7 years 8 months post-retention his PAR score had increased to 21, his DHC to $3 \mathrm{~d}$ and his AC score to 6 . His net percentage reduction in PAR score was $60.8 \%$, so he would still fall into the greatly improved category due to the very high initial PAR score. The crowding and midline shift has reproduced itself, particularly in the lower arch.

\section{Case 2 (Fig. 2)}

This case represents a mild class III malocclusion with an anterior crossbite (Pre-treatment PAR score 29, DHC 4c, AC 7). Following treatment with fixed appliances (non-extraction) the PAR score was reduced to 4 ( $86.2 \%$ reduction), the DHC to $2 \mathrm{~g}$ and the $\mathrm{AC}$ to 1 . At 8.5 years post-retention there had been no change in either the PAR score or the DHC grade, and the AC grade increased to 2 .

\section{(a)}
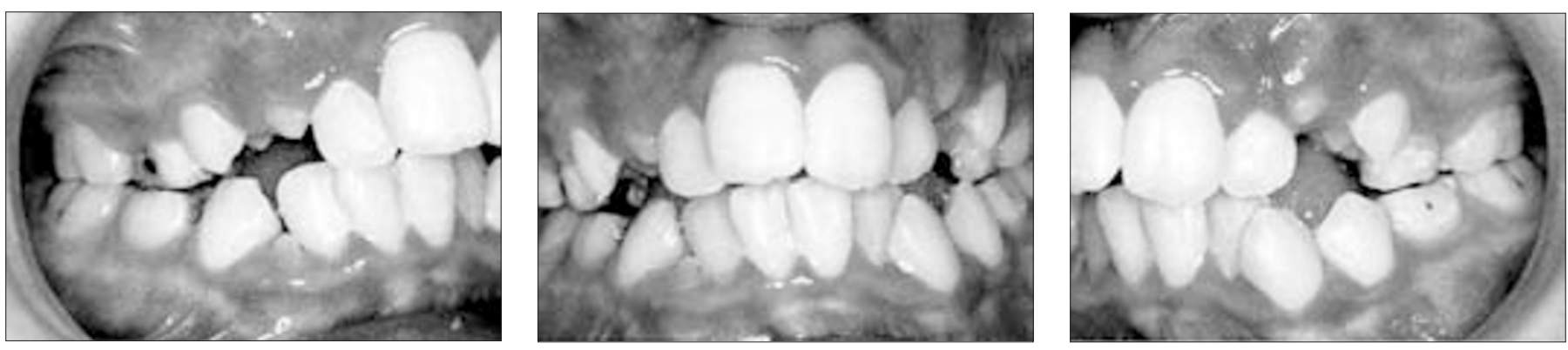

(b)
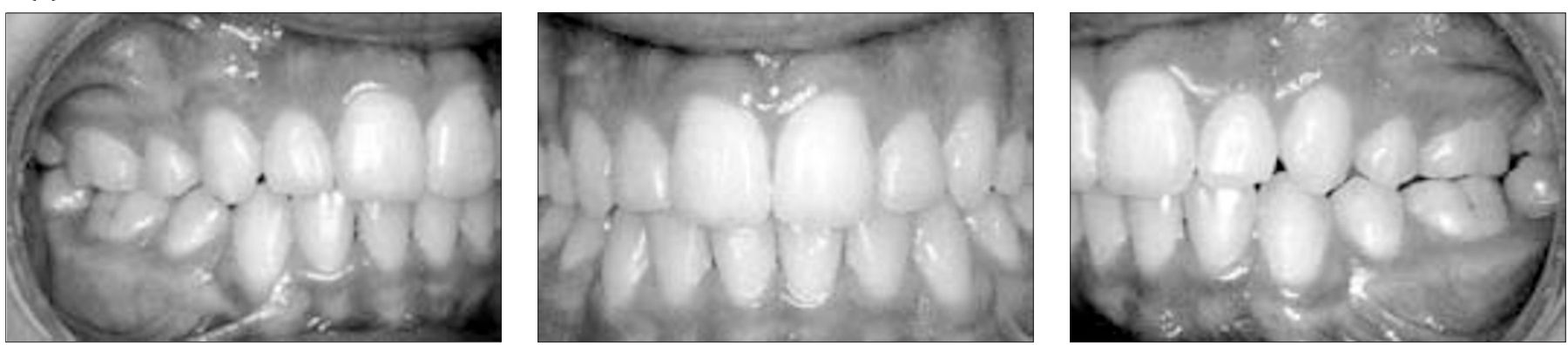

(c)
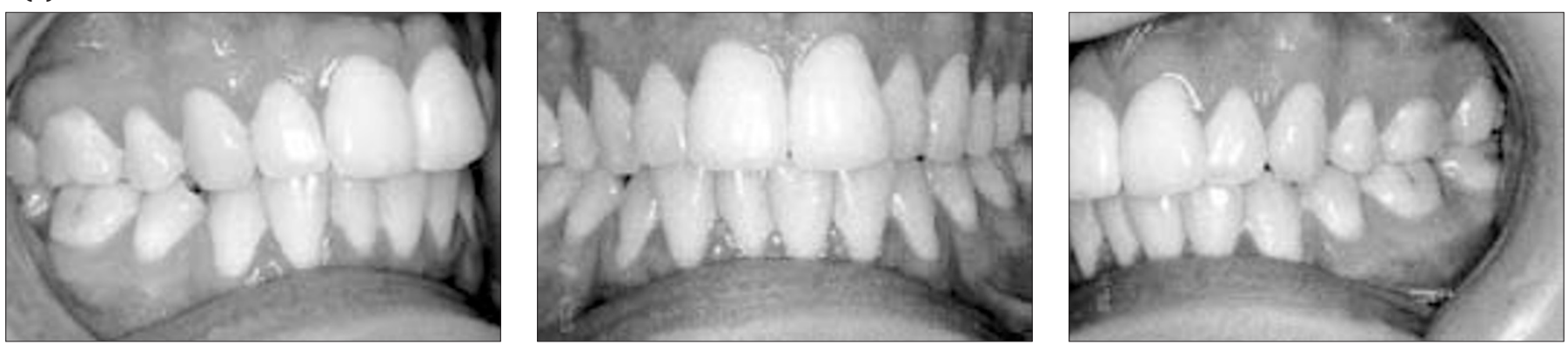

Fig. 1 Case treated using fixed appliances, extraction of first premolars and headgear. Pre-treatment (Fig. 1a), post-treatment (Fig. $1 \mathrm{~b})$ and 7 years 8 months post-retention (Fig. 1c) 
(a)

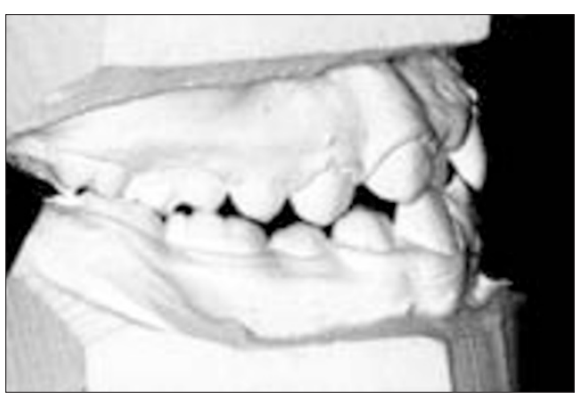

(b)
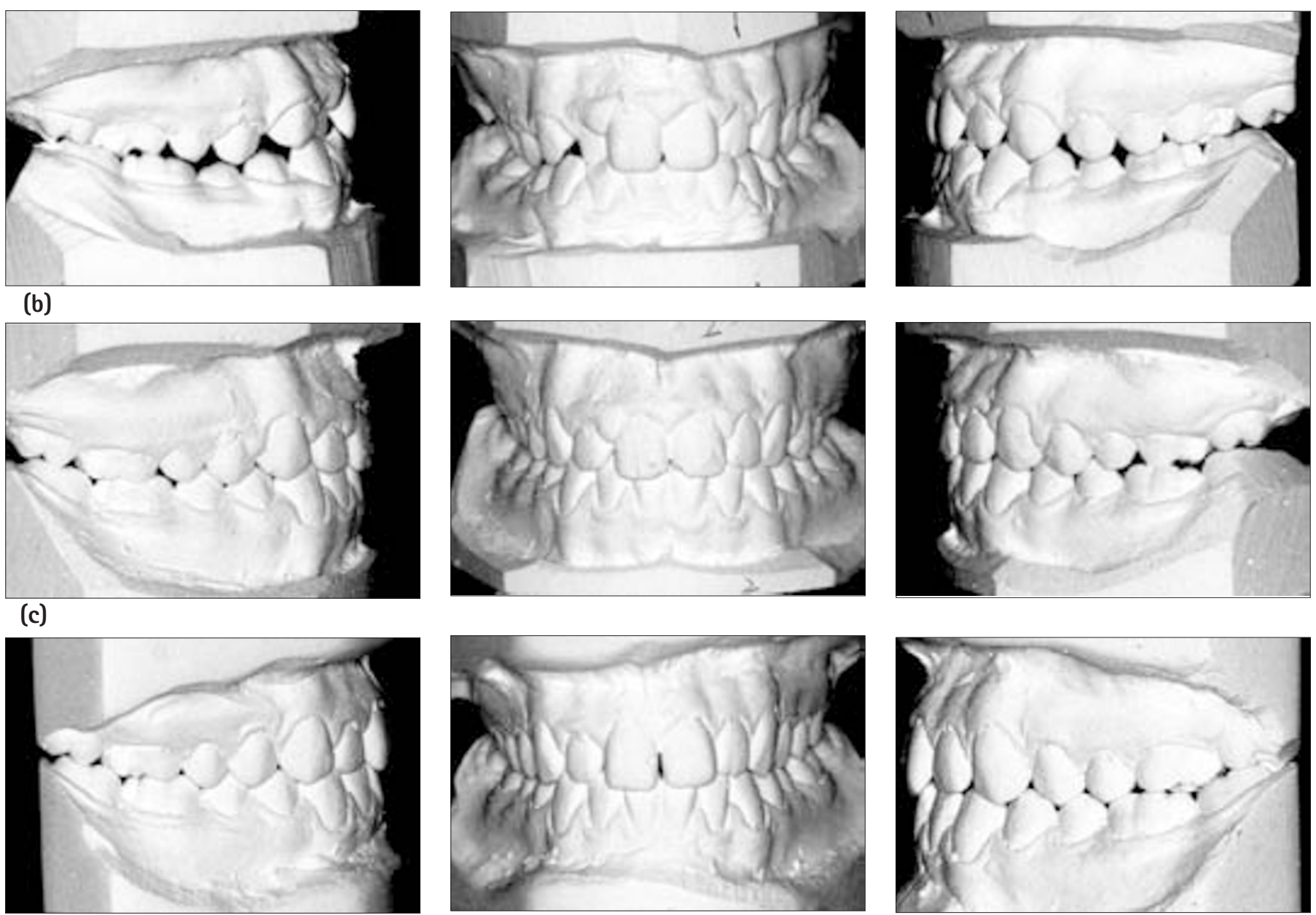

Fig. 2 Case treated non-extraction using fixed appliances. Pre-treatment (Fig. 2a), post-treatment (Fig. 2 b) and 8 years 6 months post-retention (Fig. 2c)

\section{DISCUSSION}

It was disappointing that only 78 of the original 100 cases could be followed up. One can only speculate about the long-term outcome of the cases that did not attend.

Berg $^{25}$ likened improvement in orthodontic occlusion with improvement in general orthopaedics in which the degree of improvement of the patients' particular handicap is frequently expressed as a percentage of the ideal. Expressing improvement as a percentage is therefore not unique to orthodontics.

PAR and IOTN are internationally accepted occlusal indices. The use of PAR and IOTN to grade outcome in a mixed appliance cohort of 100 consecutively started cases in the UK affords this study good reliability and allows the findings to be understood by a broad range of people. Comparison of these findings with those from earlier studies is therefore possible due to the standardised convention for recording the scores. The inclusion of all cases started, in preference to only those reaching completion of treatment, makes these findings more representative of true life than studies examining consecutively finished or randomly selected cases.

Residual need for treatment was detected by IOTN in the postretention phase. The fact that fewer patients registered need on aesthetic grounds than on dental health grounds supports the evidence of AC scores reducing over time. ${ }^{10}$ It was, however, disappointing to note that after embarking on treatment once, almost a quarter of patients will subsequently have an objective need for treatment in the future.

Similarly, Table 2 compares the percentage reduction in PAR score at the start, end and at least 5 years post-retention in this study. When these results are compared with previous studies, ${ }^{13,14,17,18}$ they appear less favourable. These differences may be attributed to the fact that this current study included cases treated with removable appliances and also discontinued cases. It was, however, reassuring to establish that at a mean post-retention time of 6.5 years $84 \%$ of cases treated were still improved or greatly improved.

It was not surprising to note that dual arch fixed appliance cases offered the greatest benefit in terms of mean PAR reduction at end of treatment and post-retention. Previous UK studies have consistently reported similar findings. ${ }^{4,5}$

To expect all patients to benefit significantly from any type of medical or dental intervention all of the time is unrealistic. For example not all hip replacements or coronary by-pass operations are successful. In dentistry 50\% of amalgam restorations have been shown to fail within 5 years ${ }^{26}$ and $3 \%$ of metallo-ceramic crowns fail before 10 years. ${ }^{27}$ Inevitably in orthodontics posttreatment changes will occur and patients must be informed about this.

It was hoped that this study might enable us to predict which types of malocclusion are most prone to relapse, so that 'therapeutic' treatments with a known beneficial effect can be chosen. ${ }^{28}$ The arbitrary pattern of relapse seen in this study once again reinforces the unpredictability of post-treatment changes. The only way to prevent such changes is to consider long-term or even permanent retention. The evidence presented suggests the appropriate use of dual arch fixed appliances will offer orthodontic patients the greatest long-term benefit. 
The authors wish to thank Mr T. Gordon Bennett, Mr Nigel E. Carter and Dr Peter H. Gordon (Consultants in Orthodontics, Newcastle Dental Hospital) for allowing access to the records of patients under their care. This project was supported by a research and development grant from South Tees Acute Hospitals NHS Trust.

1. Dental Practice Board. Digest of Statistics1999/2000.

2. DHSS. Report of the Committee of Enquiry into Unnecessary Dental Treatment. London: HMSO, 1986

3. DHSS. Report of the Occlusal Index Committee. Report No. 92821/1/48-3. London: HMSO, 1987.

4. Richmond S, Shaw W C, Roberts C T, Andrews M. Orthodontics in the General Dental Service of England and Wales: A critical assessment of standards. Br Dent J 1993; 174: 315-329

5. O'Brien K D, Shaw W C, Roberts C T. The use of occlusal indices in assessing the provision of orthodontic treatment by the hospital orthodontic service of England and Wales. Br J Orthod 1993: 20: 25-35.

6. Harrison J E. Evidence-based orthodontics: Where do I find the evidence? J Orthod 2000; $27: 71-78$

7. Cannavina C D, Cannavina G, Walsh T F. Effects of evidence-based treatment and consent on professional autonomy. Br Dent J 2000; 188: 302-306.

8. Al Yami E A, Kuijpers-Jagtman A M, van 't Hof M A. Assessment of biological changes in a nonorthodontic sample using the PAR index. Am J Orthod Dentofacial Orthop 1998; 114: 224-228.

9. Birkeland K, Boe O E, Wisth P J. Relationship between occlusion and satisfaction with dental appearance in orthodontically treated and untreated groups. A longitudinal study. Eur J Orthod 2000; 22: 509-518.

10. Cooper S, Mandall N A, DiBiase D, Shaw W C. The reliability of the index of orthodontic treatment need over time. J Orthod 2000; 27: 47-53.

11. Fox N A. The first 100 cases: A personal audit of orthodontic treatment assessed by the PAR (Peer Assessment Rating) index. Br Dent J 1993; 174: 290-297.

12. Artun J, Garol J D, Little R M. Long-term stability of mandibular incisors following successful treatment of Class II, Division 1, malocclusions. Angle Orthod 1996; 66: 229-238.

13. Birkeland K, Furevik J, Boe 0 E Wisth P J. Evaluation of treatment and post-treatment changes by the PAR Index. Eur J Orthod 1997; 19: 279-288.
14. Al Yami E A, Kuijpers-Jagtman A M, van 't Hof M A. Stability of orthodontic treatment outcome: follow-up until 10 years postretention. Am J Orthod Dentofacial Orthop 1999; 115: 300-304

15. Canut J A, Arias S. A long-term evaluation of treated Class II division 2 malocclusions: a retrospective study model analysis. Eur J Orthod 1999; 21: 377-386.

16. Little R M. Stability and relapse of mandibular anterior alignment: University of Washington studies. Semin Orthod 1999; 5: 191-204.

17. Berset G P, Eilertsen I M, Lagerstrom L, Espeland L, Stenvik A. Outcome of a scheme for specialist orthodontic care. Swed Dent J 2000; 24: 39-48.

18. Woods M, Lee D, Crawford E. Finishing occlusion, degree of stability and the PAR index. Aust Orthod J2000; 16: 9-15.

19. Ngan P, Yiu C. Evaluation of treatment and posttreatment changes of protraction facemask treatment using the PAR index. Am J Orthod Dentofacial Orthop 2000; 118: 414-420.

20. Little R M, Riedal R A, Stein A. Mandibular arch length increase during the mixed dentition: postretention evaluation of stability and relapse. Am J Orthod Dentofacia Orthop 1990; 97: 393-404

21. Richmond S, Shaw W C, Stephens C D, et al. The development of the PAR index (Peer Assessment Rating): reliability and validity. Eur J Orthod 1992; 14: 125-139.

22. Richmond S, Shaw W C, Roberts C T, Andrews M. The PAR (Peer Assessment Rating): methods to determine outcome of orthodontic treatment in terms of improvement and standards. Eur J Orthod 1992; 14: 180-187.

23. Kerr W J S, Buchanan I B, McColl J H. Use of the PAR index in assessing the effectiveness of removable appliances. Br J Orthod 1993; 20: 351-357.

24. Fox N A, Chadwick S C. The first 100 cases of orthodontic treatment: one year out of retention. Dent Update1994; 27: 288-297.

25. Berg R. Evaluation of orthodontic results - a discussion of some methodological aspects. Angle Orthod 1991; 61:261-266.

26. Elderton $\mathrm{R} \mathrm{J}$. Longitudinal study of dental treatment in the general dental service in Scotland. BrDent J 1983; 155: 91-96.

27. Walton TR. A 10-year longitudinal study of fixed prosthodontics: clinical characteristics and outcome of single-unit metal-ceramic crowns. Int J Prosthodont 1999; 12: 519-526.

28. Capron A. In McNeill P. The Ethics and Politics of Human Experimentation. pp 126. Cambridge Press, 1993 